\title{
Enhanced Fecal Excretion of Selected Immune Factors in Very Low Birth Weight Infants Fed Fortified Human Milk ${ }^{1}$
}

\author{
RICHARD J. SCHANLER, RANDALL M. GOLDBLUM, CUTBERTO GARZA, AND \\ ARMOND S. GOLDMAN \\ Section of Neonatology and USDA/ARS Children's Nutrition Research Center, Department of Pediatrics, Baylor \\ College of Medicine, Houston, Texas 77030 and Departments of Pediatrics and Human Biological Chemistry \\ and Genetics, University of Texas Medical Branch, Galveston, Texas 77550
}

\begin{abstract}
The amounts of lactoferrin, lysozyme, total IgA, secretory IgA (SIgA), and specific SIgA antibodies to a pool of Escherichia coli $O$ antigens were measured in 96h collections of feces obtained from 28 very low birth weight infants, 28-30 wk of gestation, studied at 2.5 and 6 wk of age. Eighteen of these infants were fed their mothers' milk fortified with fractions of skim and cream derived from pasteurized, lyophilized, mature human milk (FM) and 10 infants were fed commercial cow's milk-based formula. The concentrations of these selected immune factors in the FM and formula also were measured. Specific SIgA antibodies to $E$. coli $O$ antigens were detected in the feces of $90 \%$ of the FM-fed infants, but in none of the feces of the formula-fed infants. The feces obtained from FM-fed infants had markedly greater quantities of lactoferrin $(p<0.001)$, lysozyme $(p=0.006)$, and IgA $(p<$ 0.001) than those of cow's milk formula-fed infants. The concentrations of total and secretory IgA were correlated significantly $(r=0.88, p<0.001)$ and $95 \%$ of total $\operatorname{IgA}$ was SIgA. The fecal concentration of specific SIgA antibodies to $E$. coli $\mathrm{O}$ antigens in FM-fed infants correlated with the concentration of these antibodies in their milk ( $p$ $<0.001)$. However, there were no direct relationships between the milk concentrations or the infants' intakes of the other selected immune factors and the excretion of these factors in the feces. Significant relationships were noted among the immune factors in the feces, but not among the concentrations of these factors in the fortified human milk. The increased quantity of selected immune factors in the feces of very low birth weight infants fed FM may have resulted not only from passive ingestion and persistence of these factors throughout the gastrointestinal tract but also from endogenous synthesis induced by the feeding of human milk. (Pediatr Res 20: 711-715, 1986)
\end{abstract}

\section{Abbreviations}

VLBW, very low birth weight

FM, fortified human milk

Received September 30, 1985; accepted March 13, 1986.

Address all correspondence to Richard J Schanler, MD. Assistant Professor of Pediatrics, Department of Pediatrics, Baylor College of Medicine, 6608 Fannin, Suite 501, Houston, TX 77030.

This research is supported by a contract (NO1-HD-2-2814) from the National Institutes of Health and by the USDA/ARS Children's Nutrition Research Center, Department of Pediatrics, Baylor College of Medicine and Texas Children's Hospital. This project has been funded in part with federal funds from the United States Department of Agriculture, Agricultural Research Service under Cooperative Agreement 58-7MNI-6-100.

The contents of this publication do not necessarily reflect the views or policies of the United States Department of Agriculture, nor does mention of trade names, commercial products, or organizations imply endorsement by the United States Government.
SIgA, secretory IgA

EID, electroimmunodiffusion

ELISA, enzyme-linked immunosorbent assay

The decision to feed human milk to VLBW infants often is based on the potential enhancement of host defense. Two approaches have been used in the few studies designed to evaluate the protection afforded by feeding human milk to these infants: 1) assessment of morbidity and 2) the measurement of the concentrations of specific immune factors in serum, saliva, and feces of infants fed either human milk or cow's milk-based formulas (1-4). Most epidemiologic studies of morbidity in fullterm infants usually have concluded that breast-feeding is protective, but interpretations of these reports often have been confounded by uncontrolled demographic variables (5). Assessments of morbidity in VLBW infants have focused on sepsis and necrotizing enterocolitis. No consistent benefits have been reported (6-8). Concentrations of immunoglobulins in the serum were similar in both groups or elevated in VLBW infants fed cow's milk preparations (9-11).

The effects of human milk feeding on fecal excretion of lactoferrin, lysozyme, and SIgA have been reported (1-3). Fecal levels of these selected immune factors are greater in infants fed human milk than in those fed a formula (1-3). In that regard, these selected factors also resist proteolytic digestion $(12,13)$. These observations suggest that the factors remain intact throughout the infant's gastrointestinal tract. The few studies of immune factors in the feces of VLBW infants, however, have been of short duration and have not been designed to evaluate the effects of the quantity of immune factors fed, variations in nutrient intakes that would influence growth and maturation (1, 2 ), or intrinsic differences in the characteristics of the population studied, such as gastrointestinal absorptive capacity. Furthermore, the impact of augmented levels of lactoferrin, lysozyme, and SIgA in milk obtained from women delivering prematurely has not been considered in the design of most published clinical evaluations $(14,15)$. Ideally, a study of the effects of human milk on premature infants should be carried out with breast-fed infants. This study condition is precluded in VLBW infants because of their difficulties in suckling and their nutritional needs that may not be met by the nutrient concentrations of human milk (16).

Our investigations of the effects of feeding human milk to VLBW infants began with detailed assessments of the levels and stability of selected nutritional and immune factors during the collection, storage, heat processing, and fractionation of human milk (17-20). A protocol to fortify human milk was developed 
from these studies and initial clinical trials indicated that fresh human milk fortified with human milk components provided metabolizable energy levels which met the estimated needs of VLBW infants and resulted in growth and nitrogen retentions similar to those of corresponding periods of intrauterine life (16). These findings provided an impetus for studies of the immunologic effects of fortified human milk.

The objectives of the current investigation were 1) to compare the fecal excretion of lactoferrin, lysozyme, total IgA, SIgA, and SIgA antibodies to a pool of Escherichia coli $\mathrm{O}$ antigens relative to the levels which were ingested and 2) to examine the relationship between the fecal output of these selected immune factors and the infants' general gastrointestinal absorptive capacity and growth.

\section{METHODS}

Design. Twenty-eight healthy VLBW infants who met the following criteria were selected for study: 28 to $30 \mathrm{wk}$ gestation; appropriate growth for gestational age; absence of congenital abnormalities and cardiopulmonary, infectious, or gastrointestinal disorders; and tolerance to complete enteral feedings by 15 days of life. Assignment to the group fed FM or cow's milk formula was based on parental decision and the feasibility of transporting fresh milk to the nursery each morning. Informed consent was obtained and the study was approved by the human investigation review board.

Infants were studied during two feeding periods (16). In the first, they were fed either FM or formula (Similac PM 60/40, Ross Laboratories, Columbus, $\mathrm{OH}$ ) by continuous nasogastric infusion for approximately $3 \mathrm{wk}$. During the second period, infants were fed FM or formula (Similac 24, Ross Laboratories) by intermittent nasogastric bolus until they achieved a body weight of $1800 \mathrm{~g}$. The continuous infusion was designed to ensure that the entire contents of each feeding syringe were delivered to the infant. The formula-fed group received no human milk. Each preparation was fed for a minimum of 1 wk before beginning a continuous 96-h collection of feces and a precise measurement of intake. These studies were performed at approximately 2.5 and $6 \mathrm{wk}(16)$. Total nitrogen, energy, lactoferrin, lysozyme, total IgA, SIgA, and SIgA antibodies to a pool of E. coli $\mathrm{O}$ antigens were measured in feces and in aliquots of milk collected during the $96 \mathrm{~h}$. Metabolizable energy and the absorption and retention of nitrogen were estimated. The infants were supported throughout the study in a neutral thermal environment maintained by servocontrolled incubators. The clinical course and growth of each infant were monitored daily.

Preparation of FM. FM was prepared daily by adding skim and cream fractions derived from pasteurized, lyophilized, mature, donor human milk to fresh milk from each infant's mother (16). In this way, energy and nitrogen concentrations were attained that were similar to those of the cow's milk-based formulas. The daily preparation of fresh FM avoided changes which occur from long-term storage of human milk $(17,18)$.

Measurement of intake and output. Intakes were determined by weighing all feeding syringes before and after use. Ashless filter papers used to wipe buttocks and collect spills and regurgitations were saved for analysis. Milk residue in the feeding syringes and the contents of filter papers were analyzed for energy, nitrogen, and minerals. Negligible amounts were recovered, and, therefore the immune factors in these samples were not analyzed $(16,21)$. Carmine red markers were administered at the beginning and end of the 96-h collection interval. Feces were collected directly into plastic bags (U-Bag, Hollister, Inc. Libertyville, IL) and stored at $-20^{\circ} \mathrm{C}$. Fecal samples were thawed, pooled, and homogenized before analysis.

Chemical methods. Milk and feces were analyzed for total nitrogen by a semiautomated Kjeldahl method (Tecator, Herndon, VA) and for energy by bomb adiabatic calorimetry (Parr Instrument Co., Moline, IL).
Immunologic methods. Total and secretory IgA in milk and fecal extracts were determined by quantitative immunofluorescence assays using an anti- $\alpha$ detector and an antisecretory component detector, respectively (18). Lactoferrin and lysozyme were determined in milk by EID using monospecific antisera to these proteins (18). Because of their lower concentrations, solid phase ELISA was used to measure lysozyme and lactoferrin in the feces. In this sandwich assay, serial dilutions of the fecal extracts were performed in microtiter wells coated with the IgG fraction of the antisera (Accurate Chemicals, Hicksville, NY). After washing with a saline solution containing the detergent Tween 20 $(0.5 \%$, Sigma Chemical Co., St. Louis, MO), the same antibodies conjugated to horseradish peroxidase were added. The amount of the bound conjugate was determined using $o$-phenylenediamine as substrate. The activity in each well was plotted on semilog paper and compared with that produced by the same standard used in the EID. The correlation between the ELISA and EID methods was estimated by analyzing 25 milk samples by both methods. The correlation coefficients were 0.91 for lactoferrin and 0.78 for lysozyme. The coefficients of variation for the lactoferrin and lysozyme assays on 12 milk samples were 9.4 and $13.1 \%$, respectively. Secretory IgA antibodies to a pool of $E$. coli $\mathrm{O}$ antigens were measured by an ELISA assay utilizing antihuman secretory component antiserum complexed to horseradish peroxidase as the detector (18). These antibody levels were presented as a percent of a pool of human colostrum (22).

Data analyses. The measurements of immune factors in milk and feces were not distributed normally. Statistical analyses, therefore, were performed on natural logarithmic transformations of the data. Analysis of variance for repeated measures, Student's $t$ test, and multiple linear regression were used (23). Data in the text and tables, unless otherwise indicated, are expressed as the median; the values corresponding to the 25 th and the 75th quartiles are given in parenthesis adjacent to the median.

\section{RESULTS}

Subject characteristics. Eighteen FM-fed and ten cow's milk formula-fed infants were studied. All of the cow's milk-fed infants completed two balance studies. Three of the FM-fed infants did not complete the second balance study because their mothers had problems maintaining lactation. The characteristics of each group were similar (Table 1). Growth, nitrogen absorption and retention, and metabolizable energy intake were similar between groups and to intrauterine estimates (16).

Concentrations of immune factors in milks. Neither lactoferrin, lysozyme, IgA, nor specific SIgA antibodies was detected in the cow's milk formula.

The concentrations of the immune factors in the FM were expressed as mean \pm SD (Table 2 ) to characterize the variability of the data. The coefficient of variation of these concentrations in different FM samples ranged from $41-90 \%$. Lactoferrin concentrations in FM declined significantly (Table 2) from the first to the second feeding period, $2.4(2.2 ; 3.2)$ and $1.6(1.1 ; 2.2) \mathrm{mg} /$ $\mathrm{ml}$, median (25 and 75 th quartiles), respectively. Differences between pre- and postfortification concentrations of lactoferrin were less than the intraassay variability. Lysozyme concentrations were similar in both periods, $0.2(0.09 ; 0.26) \mathrm{mg} / \mathrm{ml}$. The median increase in the concentration of lysozyme following fortification was $69 \%$ (range 0 to $100 \%$ ) above prefortification values. Total IgA concentrations declined significantly from the first to the second feeding period, $1.5(0.9 ; 2.5)$ and $1.0(0.8 ; 1.1)$ $\mathrm{mg} / \mathrm{ml}$, respectively. Differences between pre- and postfortification concentrations of total IgA were less than intraassay variability. Only total IgA data are reported because the concentrations of total IgA and SIgA in FM were correlated highly $(r=$ $0.88, p<0.001$ ) and SIgA accounted for $95 \%$ of total IgA. Secretory $\operatorname{IgA}$ antibodies to a pool of $E$. coli $\mathrm{O}$ antigens were detected in all samples of FM, $10(4 ; 24) \%$ pool. The concentra- 
tions of total $\mathrm{N}$ in the mother's milk increased after fortification by $31 \pm 9 \%$ (mean $\pm \mathrm{SD})$.

Intakes and fecal excretion of immune factors. The data for the 96-h intakes and fecal excretions of lactoferrin, lysozyme, total IgA, and specific SIgA antibodies for the first and second collection periods were combined because no differences between periods were detected (Table 3 ). Significantly greater quantities of lactoferrin, lysozyme, total IgA, and specific SIgA antibodies were ingested and excreted in the feces by FM-fed infants (Table 3 ). Although total fecal $\mathrm{N}$ excretions and fecal volumes were similar between groups (Table 1), the sums of the selected fecal immune factors for group FM and the cow's milk formula group were 29 versus $1 \mathrm{mg} / 100 \mathrm{mg} \mathrm{N}$, respectively, $(p<0.001)$.

Secretory IgA antibodies to a pool of $E$. coli $\mathrm{O}$ antigens were detected in 28 of 31 ninety-six-h fecal pools analyzed from group FM, 9(3;31)\% pool, but these coproantibodies were not found in the feces of cow's milk formula-fed infants.

The fecal excretion of individual immune factors, expressed as a percent of the intake of each respective factor in the FM group (estimated from data in Table 3), was lactoferrin, 3\% $(1 ; 7 \%)$; lysozyme, $0.1 \%(0.02 ; 0.2 \%)$; and total IgA, $9 \%(4 ; 12 \%)$. Fecal N, expressed as a percent of intake (calculated from Table 1 ), was significantly greater than any of these values (mean \pm $\mathrm{SD}, 17 \pm 5 \%, p<0.01)$. None of these measurements of fecal excretion differed between collection periods.

Associations were examined between the degree of $\mathrm{N}$ fortification and the concentrations of immune factors in the FM. The concentrations of SIgA antibodies to $E$. coli $\mathrm{O}$ antigens correlated positively with the amount of $\mathrm{N}$ added to fortify the milk ( $r=$ $0.55, p<0.001)$. Associations also were sought among the

Table 1. Profile of study infants*

\begin{tabular}{|c|c|c|c|c|}
\hline & \multicolumn{4}{|c|}{ Group } \\
\hline $\begin{array}{c}\text { Subjects }(n) \\
\text { Birth wt }(\mathrm{g}) \\
\text { Gestational age (wk) }\end{array}$ & \multicolumn{2}{|c|}{$\begin{array}{c}\text { Fortified human } \\
\text { milk } \\
18 \\
1175 \pm 146 \\
29 \pm 1\end{array}$} & \multicolumn{2}{|c|}{$\begin{array}{c}\text { Formula } \\
\begin{array}{c}10 \\
1201 \pm 78 \\
29 \pm 1\end{array}\end{array}$} \\
\hline Collection period & $\begin{array}{c}\text { First } \\
(n=18)\end{array}$ & $\begin{array}{l}\text { Second } \\
(n=15)\end{array}$ & $\begin{array}{c}\text { First } \\
(n=10)\end{array}$ & $\begin{array}{l}\text { Second } \\
(n=10)\end{array}$ \\
\hline Age at study (day) & $17 \pm 3$ & $35 \pm 6$ & $16 \pm 1$ & $35 \pm 5$ \\
\hline Milk intake $(\mathrm{g} / \mathrm{kg} /$ day $)$ & $130 \pm 7$ & $160 \pm 6$ & $126 \pm 7$ & $160 \pm 11$ \\
\hline $\begin{array}{l}\text { Total nitrogen intake } \\
(\mathrm{mg} / \mathrm{kg} / \text { day })\end{array}$ & $459 \pm 42$ & $442 \pm 35$ & $459 \pm 39$ & $543 \pm 65$ \\
\hline $\begin{array}{l}\text { Fecal nitrogen }(\mathrm{mg} / \mathrm{kg} / \\
\text { day) }\end{array}$ & $81 \pm 23$ & $71 \pm 21$ & $73 \pm 18$ & $68 \pm 18$ \\
\hline Nitrogen absorption (\%) & $82 \pm 5$ & $84 \pm 3$ & $84 \pm 5$ & $87 \pm 3$ \\
\hline $\begin{array}{l}\text { Fecal energy }(\mathrm{kcal} / \mathrm{kg} / \\
\text { day) }\end{array}$ & $25 \pm 9$ & $18 \pm 11$ & $24 \pm 10$ & $17 \pm 7$ \\
\hline Fecal output $(\mathrm{g} / \mathrm{kg} /$ day $)$ & $10 \pm 3$ & $9 \pm 5$ & $11 \pm 4$ & $8 \pm 4$ \\
\hline Transit time $(\mathrm{h}) \dagger$ & $24 \pm 6$ & $27 \pm 12$ & $35 \pm 17$ & $28 \pm 11$ \\
\hline
\end{tabular}

* Data are presented as the mean $\pm \mathrm{SD}$.

$\dagger$ Gastrointestinal transit time as measured by carmine red: average of first and second markers. concentrations of immune factors in FM. The concentration of lactoferrin, during the first balanced study, correlated positively with the concentration of $\mathrm{N}(r=0.72, p<0.001)$.

The influence of the intake of immune factors on fecal excretion was examined in two ways. 1) Correlations were tested between the amounts of specific factors ingested and excreted. A significant relationship was detected only between milk and fecal levels of SIgA antibodies to E. coli $(r=0.79, p<0.001)$. 2) Data were examined to determine if the intake of specific immune factors or $\mathrm{N}$ influenced the fecal excretion of other factors. The fecal excretion of lysozyme was correlated positively with the titer of SIgA antibodies to $E$. coli in the milk $(r=0.61, p<$ $0.001)$ and negatively with the intakes of total $\operatorname{IgA}(r=-0.48, p$ $<0.01)$ and $\mathrm{N}(r=-0.61, p<0.001)$.

The relationships among the fecal excretions of the various immune factors were tested. Despite the absence of any significant associations among the factors in FM, several significant relationships were detected among fecal levels. The levels of lactoferrin, lysozyme, total $\operatorname{IgA}$, and specific SIgA antibodies were correlated positively with each other $(r=0.45-0.65, p<$ 0.01 for all comparisons). No correlations were detected between the levels of excretion of any of the measured immune factors and total fecal energy, fecal $\mathrm{N}$, fecal volume, body weight, or gastrointestinal transit time except that fecal $\mathrm{N}$ was correlated positively with total $\operatorname{IgA}(r=0.45, p<0.01)$. The fecal excretion of the selected immune factors in the cow's milk formula group was not correlated with $\mathrm{N}$ intake, transit time, or fecal $\mathrm{N}$ excretion, nor were these measures correlated with one another.

\section{DISCUSSION}

The fecal excretion of selected immune factors was significantly greater in VLBW infants fed FM than in infants fed formula. Because growth, nitrogen absorption and retention, and metabolizable energy intake were similar between groups, it is unlikely that any differences in the quantity of immune factors

Table 3. Intake and fecal excretion of selected immune factors*

\begin{tabular}{lcc}
\hline & \multicolumn{2}{c}{ Group } \\
\cline { 2 - 3 } Component & $\begin{array}{c}\text { Fortified human milk } \\
(\mathrm{n}=33)\end{array}$ & $\begin{array}{c}\text { Formula } \\
(\mathrm{n}=20)\end{array}$ \\
\hline Lactoferrin $(\mathrm{mg} / \mathrm{kg} / 96 \mathrm{~h})$ & & \\
$\quad$ Milk & $1234(794 ; 1504)$ & 0 \\
Feces & $37(13 ; 59)$ & $0.2(0.1 ; 0.4)$ \\
Lysozyme $(\mathrm{mg} / \mathrm{kg} / 96 \mathrm{~h})$ & $80(50 ; 140)$ & 0 \\
$\quad$ Milk & $0.07(0.02 ; 0.14)$ & $0.009(0.001 ; 0.018)$ \\
Feces $\dagger$ & $654(471 ; 918)$ & 0 \\
Total IgA (mg/kg/96 h) & $58(18 ; 89)$ & $2(1 ; 5)$ \\
Milk &
\end{tabular}

* Data presented as the median and in parentheses as the 25 th and 75th quartile. Natural logarithmic transformations of the data were performed only for statistical analyses. Fortified human milk versus formula, $p<0.001$ for all comparisons between milks and between feces, except $\dagger p=0.006$.

Table 2. Concentrations of immune factors in $F M^{*}$

\begin{tabular}{lcc}
\hline \multicolumn{1}{c}{ Immune factor } & First balance study & Second balance study \\
\hline Lactoferrin $\dagger$ & $2.82 \pm 1.15$ & $1.63 \pm 0.75$ \\
Lysozyme & $0.21 \pm 0.19$ & $0.19 \pm 0.14$ \\
Total IgA $\dagger$ & $1.74 \pm 1.15$ & $1.04 \pm 0.50$ \\
SlgA $\dagger$ & $1.57 \pm 1.26$ & $1.08 \pm 0.58$ \\
SlgA antibodies to E. coli 0 antigens & $18 \pm 22$ & $20 \pm 26$ \\
\hline \% pool & & \\
\hline
\end{tabular}

\footnotetext{
* The results (mean $\pm \mathrm{SD}$ ) are expressed as $\mathrm{mg} / \mathrm{ml}$ except for SIgA antibodies which are expressed as the percent of antibody activity in a reference pool of colostrum.

$\dagger$ Significant decrease from first to second balance study, $p<0.01$.
} 
in the recipient's stools were due to nutritional effects (16). Several other explanations for the greater excretion of immune factors in the FM group were considered. The differences may have been due to the greater intakes of human immune factors by the FM group. Indeed, our assays did not detect any of the factors in the cow's milk-based formula. A further explanation for the greater excretion of immune factors by group FM may be due to the resistance of selected human milk proteins to proteolytic digestive enzymes $(12,13)$. These possibilities were considered in more detail.

The protocol for preparing the FM was effective in maintaining or exceeding preterm milk concentrations of these immune factors. The concentrations of lactoferrin, total IgA, SIgA, and specific SIgA antibodies were within the range reported for preterm milk obtained at 2 to 3 and 6 to 7 postnatal wk $(14,15)$. The lysozyme concentration in FM was approximately twice the value reported for preterm milk (14). The increment in the postfortification concentration of lysozyme may have resulted from the type of donor milk used in the processing. This milk was obtained generally beyond the 3rd postpartum month or during gradual weaning. The lysozyme content of the milk, in both situations, may be greater than that found in milk collected earlier in lactation $(24,25)$. In addition, the rapid, high-temperature treatment used to reduce microbial contamination significantly increases the measurable concentration of lysozyme, but does not affect the concentrations of lactoferrin, IgA, and SIgA antibody activity (19). The concentrations of selected immune factors, therefore, were preserved in the FM. The concentrations achieved in FM and the greater volume of milk intake per kilogram body weight resulted in greater intakes of lactoferrin, lysozyme, and IgA than those reported for full-term infants fed human milk for the first 2 months of life (26).

The resistance of human milk proteins to proteolysis was evaluated by comparing the intake and the excretion of the factors. The only relationship found between the quantities ingested and excreted was that for specific SIgA antibodies to $E$. coli $\mathrm{O}$ antigens. Specific antibody activity, therefore, appears to be maintained after processing, feeding, and passage of FM through the gastrointestinal tract. This has been observed for blood group agglutinins and antibodies to other microorganisms in human milk fed to infants $(2,13,27)$.

The absence of correlations between milk concentrations or intakes and the fecal excretions of lactoferrin, lysozyme, and IgA in group FM, however, is not consistent with the conclusion that a greater intake of immunologic factors is the sole explanation for the enhanced excretion of these components. This led us to question whether human milk stimulates the intestinal synthesis or diminishes destruction of these factors. Positive correlations among the fecal immune factors and the absence of significant associations between the amounts of the ingested immunologic components and those excreted support the former possibility. Although these findings do not prove a cause and effect relationship, they suggest that human milk may contain stimulators of mucosal immune maturation.

Certain methodologic issues must be weighed in considering these possibilities. First, wtih the exception of the ELISA for SIgA antibodies, the immunochemical assays used in this study may have detected fragments as well as intact proteins. If that were the case, the amounts of certain immunologic factors in the feces may have been overestimated. We hope to shed additional light on that question in subsequent studies that employ methods to estimate the molecular size of these proteins.

The second methodologic issue is whether the physical disruption of human milk which occurs during the preparation of the fortified human milk influences the bioavailability of some immunologic components. Physical disruption, for example, by centrifugation has been reported to yield increased concentrations of selected immune factors (26). The issue is confounded by 1) the undetermined extent of physical compartmentation of immune factors and how those factors are protected or presented in the recipient's alimentary tract and 2) the feeding protocol that required the avoidance of the very proximal alimentary tract. In order to explore these questions further, studies are required in which unfortified human milk is fed or infants are breast-fed.

Although enhanced fecal excretion of lactoferrin, lysozyme, total IgA, and SIgA does not prove enhanced host protection, a rationale and direction have emerged for further studies of the effects of human-milk feeding on the development of the mucosal immune system as well as studies of the fate of ingested immunologic components in human milk. When the effects of FM on the serum and urinary concentrations of these immune factors are examined or experiments with intrinsically labeled immune components are done, the issues in question may be clarified.

Acknowledgments. The authors thank Pamela Burns, R.N., for nursing assistance, Judy Hopkinson, Ph.D., for lactation management, J. Kenard Fraley and E. O'Brian Smith, Ph.D. for data and statistical advice, Jell Hse and Kimberly Hotko for their technical assistance, E. Roseland Klein for editorial advice, and Sandy Perez for manuscript preparation.

\section{REFERENCES}

1. Haneberg B, Finne P 1974 Lysozymes in feces from infants and children. Acta Paediatr Scand 63:588-594

2. Haneberg B 1974 Immunoglobulins in feces from infants fed human or bovine milk. Scand J Immunol 3:191-197

3. Spik G, Brunet B, Mazurier-Dehaine C, Fontaine G, Montreuil J 1982 Characterization and properties of the human and bovine lactotransferrins extracted from the faeces of newborn infants. Acta Paediatr Scand 71:979-985

4. Mellander L, Carlsson B, Hanson LA 1984 Appearance of secretory IgM and IgA antibodies to Escherichia coli in saliva during early infancy and childhood. J Pediatr 104:564-568

5. Sauls HS 1979 Potential effect of demographic variables and other variables in studies comparing morbidity of breast-fed and bottle-fed infants. Pediatrics 64:523-527

6. Yu VYH, Jamieson J, Bajuk B 1981 Breast milk feeding in very low birthweight infants. Aust Paediatr J 17:186-190

7. Kliegman RM, Pittard WB, Fanaroff AA 1979 Necrotizing enterocolitis in neonates fed human milk. J Pediatr 95:450-453

8. Narayanan I, Prakash K, Bala S, Verma RK, Gujral VV 1980 Partial supplementation with expressed breast-milk for prevention of infection in lowbirth-weight infants. Lancet 2:561-563

9. Savilahti E, Jarvenpaa AL, Raiha NCR 1983 Serum immunoglobulins in preterm infants: comparison of human milk and formula feeding. Pediatrics $72: 312-316$

10. Saarinen UM, Pelkonen P, Siimes MA 1979 Serum immunoglobulin A in healthy infants: an accelerated postnatal increase in formula-fed compared to breast-fed infants. J Pediatr 95:410-412

11. Stephens S, Kennedy CR, Lakhani PK, Brenner MK 1984 In-vivo immune responses of breast- and bottle-fed infants to tetanus toxoid antigen and to normal gut flora. Acta Paediatr Scand 73:426-432

12. Brines RD, Brock JH 1983 The effect of trypsin and chymotrypsin on the in vitro antimicrobial and iron-binding properties of lactoferrin in human milk and bovine colostrum. Biochim Biophys Acta 759:229-235

13. Kenny JF, Boesman MI, Michaels RH 1967 Bacterial and viral coproantibodies in breast-fed infants. Pediatrics 39:202-213

14. Goldman AS, Garza C, Nichols B, Johnson CA, Smith EO, and Goldblum RM 1982 Effects of prematurity on the immunologic system in human milk. J Pediatr 101:901-905

15. Gross SJ, Buckley RH, Wakil SS, McAllister DC, David R, Faix RG 1981 Elevated IgA concentration in milk produced by mothers delivered of preterm infants J Pediatr 99:389-393

16. Schanler RJ, Garza C, Nichols BL 1985 Fortified mothers' milk for very low birthweight infants: Results of growth and nutrient balance studies. J Pediatr 107:437-448

17. Goldblum RM, Goldman AS, Garza C, Johnson CA, Nichols BL 1982 Human milk banking II. Relative stability of immunologic factors in stored colostrum. Acta Paediatr Scand 71:143-144

18. Goldblum RM, Garza C, Johnson CA, Harrist R, Nichols BL, Goldman AS 1981 Human milk banking I. Effects of container upon immunologic factors in mature milk, Nutr Res 1:449-459

19. Goldblum RM, Dill CW, Albrecht TB, Alford ES, Garza C, Goldman AS 1984 Rapid high-temperature treatment of human milk. J Pediatr 104:380-385

20. Garza C, Johnson CA, Harrist R, Nichols BL 1982 Effects of methods of collection and storage on nutrients in human milk. Early Hum Dev 6:295303

21. Schanler RJ, Garza C, Smith EO 1985 Fortified mothers' milk for very low 
birth weight infants: results of macromineral balance studies. J Pediatr 107:767-774

22. Carlsson B, Kaijser B, Ahlstedt S, Gothefors L, Hanson LA 1982 Antibodies against Escherichica Coli capsular (K) antigens in human milk and serum Acta Paediatr Scand 71:313-318

23. Winer BJ 1962 Statistical Principles in Experimental Design, 2nd ed. McGrawHill Book Co., New York

24. Goldman AS, Garza C, Nichols BL, Goldblum RM 1982 Immunologic factors in human milk during the first year of lactation. J Pediatr 100:563-567
25. Goldman AS, Goldblum RM, Garza C, Nichols BL, Smith EO 1983 Immunologic components in human milk during weaning. Acta Paediatr Scand 72:133-134

26. Butte NF, Goldblum RM, Fehl LM, Loftin K, Smith EO, Garza C, Goldman AS 1984 Daily ingestion of immunologic components in human milk during the first four months of life. Acta Paediatr Scand 73:296-301

27. Ogra SS, Weintraub D, Ogra PL 1977 Immunologic aspects of human colostrum and milk. III. Fate and absorption of cellular and soluble components in the gastrointestinal tract of the newborn. J Immunol 119:245-248 